\title{
A importância do manual de FLE em escolas públicas estaduais no município de Macapá-AP
}

\section{Aluana Vilhena Amoras ${ }^{1}$, Mônica Miranda Oliveira de Araújo ${ }^{2}$ e Valmira dos Santos Cordeiro Alves ${ }^{3}$}

\footnotetext{
1 Especialista em Metodologia de Ensino de Língua e Literatura de Expressão Francesa pela Faculdade Apoena. Graduada em LetrasFrancês pela Universidade Federal do Amapá. Professora da rede pública de ensino do Governo do Estado do Amapá, Brasil. E-mail: aluana.amoras@gmail.com

2 Especialista em Metodologia de Ensino de Língua e Literatura de Expressão Francesa pela Faculdade Apoena. Graduada em Letras pela Universidade Federal do Ceará. Professora da rede pública de ensino do Governo do Estado do Amapá, Brasil. E-mail: monicaaraujo077@gmail.com

3 Especialista em Metodologia de Ensino de Língua e Literatura de Expressão Francesa pela Faculdade Apoena. Graduada em Letras pelo Instituto de Educação Superior do Amapá. Professora da rede pública de ensino do Governo do Estado do Amapá, Brasil. E-mail: valmira_cordeiro@hotmail.com
}

RESUMO: Este trabalho objetiva mostrar a importância de se ter um manual de FLE nas escolas públicas de Macapá-AP para auxiliar o processo de ensino-aprendizagem de língua estrangeira, uma vez que um método oferece suporte didático para professores e alunos no ensino e aprendizagem na língua alvo. Questionários foram aplicados e respondidos a professores de francês de três escolas públicas de Macapá-AP e quatro manuais foram analisados, dos quais dois são indicados como suporte pedagógico para os níveis de ensino fundamental e médios, respectivamente: Le Kiosque 1 e Taxi 1.

Palavras-chaves: Manual. FLE. Aprendizagem.

The importance of the FLE manual in state public schools in the municipality of Macapá-AP ABSTRACT: This paper aims to show the importance of having an FLE manual in public schools in Macapá-AP to support the foreign language teaching-learning process, since one method provides didactic support for teachers and students in teaching and learning in the target language. Questionnaires were applied and answered to French teachers from three public schools in Macapá-AP and four manuals were analyzed, of which two are indicated as pedagogical support for elementary and middle school levels, respectively: Le Kiosque 1 and Taxi 1.

Keywords: Manual. FLE. Learning.

\section{INTRODUÇÃO}

De acordo com os Parâmetros Curriculares Nacionais (PCNs) (BRASIL, 1998), a aprendizagem de uma língua estrangeira (LE) contribui para o processo educacional do aluno, pois possibilita mais do que a simples aquisição de um novo vocabulário: o conduz a compreender o funcionamento da linguagem, trabalha o desenvolvimento de habilidades que o auxiliam a falar/entender o que outras pessoas, em outros países, falam em determinadas situações, promovendo também que se adquira e se aceite novos valores, antes desconhecidos sobre outras sociedades.

Dentre os critérios elencados pelos PCNs (BRASIL, 1998), para se incluir uma LE no currículo escolar, devem ser observados os seguintes itens: o fator histórico, os relativos à comunidade local e os relativos à tradição. Um exemplo típico de escolha baseada no fator histórico é o idioma inglês, adotado pela maioria das escolas brasileiras em 
função da influência norte-americana na economia mundial desde o século XX.

No caso relativo às comunidades locais, podemos exemplificar com a própria Língua Portuguesa, tratada como segunda língua, por exemplo, nas comunidades indígenas em que as relações de parentescos são bastante evidentes, tornando-se desta forma importante o seu ensino.

E por último, os fatores relativos à tradição, o idioma francês, adotado em algumas escolas da rede pública do Amapá, foi escoIhido principalmente pelas relações comerciais, linguísticas e culturais que se estabelecem entre o Brasil (Amapá) e a Guiana Francesa, atualmente.

No Estado do Amapá, o ensino de língua francesa além de estar intrinsecamente ligado ao fator histórico, está, ao mesmo tempo, também relacionado à questão da proximidade do Brasil com a Guiana Francesa; com as intensificações das relações socioculturais surgiu a necessidade de se ter na maioria das escolas públicas amapaenses o francês como LE.

Como o francês é a LE adotada pela maioria das escolas públicas estaduais amapaenses, torna-se importante pensar num manual que auxilie professores e alunos no processo de ensino-aprendizagem do Francês Língua Estrangeira (FLE). Assim, a utilização de um manual de ensino é importante para aproximar o aluno à realidade da língua estrangeira por meio, por exemplo, de imagens, textos, traços culturais, linguísticos e fonológicos. Além disso, a grande maioria desta categoria de obras de idiomas traz alguns recursos complementares, como CD-ROMs, caderno de atividades, livro do aluno, livro do professor e guia pedagógico.

Mas o que se observa nas escolas públicas do município de Macapá é a ausência de um manual de FLE que oriente e sirva de modelo linguístico aos professores e alunos. Os professores de francês das escolas macapaenses, na maioria das vezes, têm que elaborar as atividades e conteúdos durante todo o ano letivo. Por esta razão, neste artigo, propõe-se debater questões relativas à importância de se ter um método de FLE que seja adotado nas escolas públicas estaduais da cidade de Macapá, atendendo às necessidades culturais, gramaticais, lexicais, fonológicas do FLE, para o ensino fundamental e médio; e assim provocar e sugerir a adoção de dois métodos, um para cada nível de ensino: fundamental e médio, destacando as vantagens para uma progressão e linearidade dos conteúdos.

Assim, o objetivo principal deste trabalho é mostrar a importância de se ter um manual de FLE nas escolas públicas estaduais localizadas em Macapá-AP, por meio de uma escolha criteriosa analisando seus principais benefícios para o processo de ensino-aprendizagem, com o intuito de indicar dois métodos a serem adotados, sendo um para o ensino fundamental e outro para o ensino médio.

\section{REFERENCIAL TEÓRICO}

\subsection{Definição de manual}

Conforme Práce (2011, p. 10), manual/método: "est une aide pédagogique et un ouvrage didactique sous un format maniable qu'on utilise dans le processus de l'enseignement et qui se rapporte en principe à une méthodologie donnée" ${ }^{1}$. Ou se-

\footnotetext{
1 Tradução nossa: "é uma ajuda pedagógica e material didático em um tamanho prático que é utilizado no processo de ensino e que se relaciona, em princípio, a uma metodologia específica".
} 
ja, é um livro cujo objetivo é facilitar a aprendizagem de uma língua estrangeira, nele havendo uma metodologia de ensino do FLE, atividades variadas, público alvo e duração do curso. Na maioria das vezes, vem acompanhado de recursos auxiliares, como CD-ROMs, livros do aluno e professor e caderno de exercícios.

Vilaça (2010) reforça a ideia de se ter um método e aponta a importância de se avaliar os manuais didáticos de FLE antes de utilizá-los em sala de aula. Assim, não se pode utilizar qualquer manual nas escolas públicas de Macapá-AP. Para esta pesquisa, utilizaremos alguns critérios para escolher os dois manuais para o ensino fundamental e médio. Tais critérios foram retirados da grade de avaliação de manual elaborada por Silva (2014).

Segundo Savli (2011), o termo método possui diferentes conceitos e varia conforme o contexto em que é utilizado, podendo ser um material de ensino (manual, CDROM), um procedimento para ensinar e aprender uma língua etc. Mas, para este trabalho, o conceito adotado é aquele que o enquadra como material pedagógico, livro, que vem acompanhado de outros recursos materiais, como livro de exercícios, CDROM, guia pedagógico.

Les manuels, selon le public à qui ils s'adressent, se divisent en deux: manuels universalistes et manuels spécifiques. SeIon Jean Pierre Cuq, les manuels universalistes sont destines à des publiques divers, tandis que les manuels spécifiques sont destinés a un public précis ou une situation particulière ${ }^{2}$ (SAVLI, 2011, p. 66).

2 Tradução nossa: Os manuais, dependendo do público a quem se dirigem, são divididos em dois: manuais universais e manuais específicos. De acordo com Jean
Além disso, um manual deve atender às perspectivas elaboradas pelas instituições de ensino, às necessidades dos alunos e metodologicamente aos anseios do professor. Estas razões fazem com que a escolha torne-se difícil, mas não impossível. Savli (2011) explica que o professor deve conhecer bem o seu público, antes de utilizar determinado manual. Desta forma, os manuais escolhidos são específicos para um público: estudantes das escolas públicas de Macapá-AP, que estão cursando o ensino fundamental e o ensino médio.

\subsection{Função do manual}

Pode-se observar que na ausência de um manual, é indiscutível que tanto o professor como os alunos terão maiores dificuldades em desenvolver suas atividades referentes ao ensino-aprendizagem de uma língua estrangeira (BESSE, 1985). Embora seja possível e plausível dizer que professores e alunos podem desenvolver o estudo de FLE, mesmo na ausência de um método, porém estes estarão deixando de utilizar as diversas ferramentas que o referido suporte didático pode oferecer aos envolvidos no processo, tais como:

Guia: quando um docente não utilizar um método, não terá uma estrutura de curso, lições e unidades organizadas, não saberá os níveis de aprendizagem do aluno, não estará orientado ao ritmo e à progressão do curso.

Suporte: o professor não terá meios concretos de atualização metodológica como atividades e tarefas.

Metodologia: na ausência do manual,

Pierre Cuq, manuais universais são destinados a públicos diferentes, enquanto que os específicos são para um público específico ou uma situação particular. 
metodologias e abordagens de ensino/aprendizagens precisam estar no conhecimento construído do professor e não serão apresentadas, com justificativas e exemplificações que não estejam em um manual metodologicamente orientado.

Modelo linguístico: o professor não terá reunido, em um único suporte, conhecimentos gramaticais, lexicais, semânticos, fonológicos e pragmáticos que servem de modelo a professores e alunos da língua estudada.

Cultural: alunos e professor não terão facilitados o acesso à cultura e aos saberes socioculturais associados a uma língua fonte, bem como ao conhecimento intercultural.

Autoaprendizagem: a ausência de um método para o aluno revisar a disciplina quando desejar, faz com que ele perca a oportunidade de verificar a sua própria progressão na aprendizagem de um idioma estrangeiro.

Avaliação: a avaliação é importante para medir o aprendizado do aluno e verificar quais assuntos devem ser mais bem trabaIhados pelos professores. Alguns manuais trazem a avaliação pronta no próprio livro que tanto pode ser utilizada pelo professor nas aulas quanto servir de modelo de elaboração de outras atividades.

No entanto, existem professores que optam pela não adoção de apenas um método, preferindo utilizar documentos autênticos, tais como: artigos de jornais, revistas, etc... Desta maneira o docente que utiliza essa metodologia, no intuito de praticar um ecletismo e de tornar o ensino mais diversificado, deve estar atento aos seus objetivos relacionados ao ensino/aprendizagem (SAVLI, 2011).

\subsection{0 que é um bom manual?}

Savli explica que a utilização de método no ensino de FLE vai muito além de uma simples escolha de um livro:

Choisir le manuel est une tache difficile que chaque enseignant devrait le prendre au sérieux pour pouvoir obtenir d'excellents résultats dans sa classe, cette perspective, certains aspects doivent être pris en compte:

a) le programme ainsi que les objectifs et les horaires fixes par l'institution.

b) les caractéristiques des apprenants telles que l'âge, le niveau, les besoins et les demandes des apprenants.

c) la concomitance de l'opinion méthodologique du manuel avec celle de l'enseignant ${ }^{3}$ (SAVLI, 2011, p. 69).

Um manual deve atender às perspectivas de ensino elaboradas pelas instituições de ensino, às necessidades dos alunos e metodologicamente aos anseios dos professores. Estas razões fazem com que a escolha torne-se difícil, mas não impossível. Savli (2011) explica que o professor deve conhecer bem o seu público, antes de selecionar e utilizar determinado manual.

Sabe-se que o manual didático é uma ferramenta muito útil no processo de ensinoaprendizagem, tanto para o professor quanto para o aluno. No entanto, é importante

3 Tradução nossa: Selecionar o manual é uma tarefa difícil que cada professor deve levar a sério a fim de alcançar excelentes resultados em sua classe, nesta perspectiva, alguns aspectos devem ser considerados:

a) o programa, os objectivos e horários fixos pela instituição.

b) as características dos alunos, como idade, nível, necessidades e demandas dos alunos.

c) a coincidência de opinião metodológica do manual com do professor.

https://periodicos.unifap.br/index.php/estacao Macapá, v. 7, n. 2, p. 77-86, maio/ago. 2017 
ressaltar que o manual deve atender às necessidades e expectativas do aprendiz, pois nem sempre o contexto sociocultural em que o aluno está inserido é respeitado. Outro fato importante que não deve ser esquecido é que o manual funciona como uma ferramenta de ensino-aprendizagem para o professor e para o aluno, ou seja, ao manual não cabe o papel de ensinar ou aprender e sim de auxiliar no referido processo.

Assim, pode-se afirmar que não existe livro didático ideal. Mesmo que a escolha do mesmo envolva atenção às necessidades do educando, seu contexto sociocultural, informação cultural diversa e não-etnocêntrica, balanceamento entre teoria e prática e linguagem apropriada, um livro didático nunca será auto-suficiente; sempre haverá necessidade de se suplementar determinadas partes do livro didático com material extra, em decorrência de fatores de importância internacional, nacional ou local que servem como fatores indutores de discussão em sala de aula, tais como a Copa do Mundo ou a implantação da Ponte Binacional entre Brasil e a Guiana Francesa.

Assim, os resultados obtidos com um manual em uma turma escolar jamais serão os mesmos em outra; cada classe é um espaço único de ensino. E um bom ou mau resultado não se dará apenas a partir da utilização de um método, no entanto, deverá ser avaliado de acordo com outros fatores tais como: a escolha do manual, a metodologia de cada professor, e também o próprio aprendiz é um fator importante no processo (TILIO, 2008).

Para ilustrar, complementarmente, o processo apresentado acima, serão apresentados a seguir os dados da pesquisa efetuada junto a professores de escolas públicas es- taduais no Estado do Amapá e a análise dos métodos conforme a grade de Silva (2014).

\section{METODOLOGIA}

Conforme Freitas e Prodanov (2013), podemos classificar esta pesquisa como pesquisa descritiva, com suporte no método qualitativo, pois os dados analisados surgiram depois da aplicação dos questionários e da avaliação de alguns manuais visando verificar deles são os mais indicados aos níveis de ensino fundamental e médio, além de verificar as reais necessidades dos professores das escolas visitadas.

Selecionaram-se três escolas públicas localizadas na cidade de Macapá-AP para a realização da pesquisa de campo. A quantidade de escolas é pequena, pois elas constituem-se em uma amostra. As escolas escoIhidas para esta pesquisa são: Escola Estadual Lucimar Amoras Del Castillo, Escola Estadual Augusto dos Anjos e a Escola Estadual Professor David Miranda, todas com oferta de ensino fundamental e médio.

Fez-se aplicação de questionário aos professores da disciplina Francês das escolas selecionadas, para obtenção de dados que ilustram a discussão deste trabalho. De acordo com Freitas e Prodanov (2013, p. 108), “o questionário é uma série ordenada de perguntas que devem ser respondidas por escrito pelo informante (respondente). O questionário, numa pesquisa, é um instrumento ou programa de coleta de dados".

De posse dos dados obtidos a partir dos questionários aplicados nas escolas, fez-se análise de alguns manuais conforme a grade de Silva (2014), e em seguida será apresentada a discussão dos métodos que mais correspondem aos critérios requisitados para adoção nos níveis de ensino fundamental e 
médio das escolas abordadas.

\section{ANÁLISE E DISCUSSÃO DOS DADOS}

\subsection{Questionários aplicados aos professo- res}

\section{A opção pelo manual}

Observou-se que todos os professores das escolas pesquisadas utilizam manual de FLE em suas aulas. A escolha está relacionada ao tempo de utilização dos mesmos, por estarem habituados aos manuais e conhecerem as atividades e conteúdos dos métodos.

\section{A importância do manual}

De acordo com os professores das escolas pesquisadas, o manual torna-se importante pela organização dos conteúdos, pela sequência didática, pelo suporte pedagógico, pela variedade de atividades que contemplam todas as competências de comunicação.

\section{Atividades privilegiadas}

A maioria dos professores declarou que desenvolve atividades contemplando as quatro competências de comunicação: compreensão oral e escrita, produção oral e escrita. Uma pequena parte disse que prioriza apenas atividades de produção escrita e oral.

\subsection{Análise dos manuais}

Vilaça (2010) reforça a ideia de se ter um método e aponta a importância de avaliar os manuais didáticos de FLE antes de utilizálo em sala de aula. Desta maneira, para esta pesquisa, utilizou-se alguns critérios para a escolha de dois manuais para o ensino fundamental e médio.

Tais critérios foram retirados da grade de avaliação de manual elaborada por Silva (2014). Para tanto, analisaram-se os seguintes manuais: Taxi 1 (TAXI, 2005), Tempo 1 (LAVENNE; BÉRARD; CANIER, 1996), Adosphère 1 (HIMBER; POLETTI, 2011) e Le Kiosque 1 (GALLON et al, 2007). Logo, a análise a seguir foi feita com base nos quatro manuais selecionados, a partir dos seguintes subitens:

Conteúdo: observou-se que os manuais apresentam uma boa sequência didática. Logo, várias competências são muito bem desenvolvidas, tais como: competências linguísticas, sociolinguísticas, culturais, situações de comunicação profissional e conteúdos temáticos. Cabe informar que o método Tempo 1 possui uma abordagem mais voltada para as competências linguísticogramatical e ortográfico do que os outros três métodos.

Atividades socioculturais: a partir das análises feitas dos manuais em questão, observou-se que os mesmos não direcionam a questão sociocultural de forma específica, ou seja, não abordam questões de cultura local, por terem sido produzidos na França e que, por isso, são voltados para um público heterogêneo, de todas as nacionalidades, tendo assim uma visão universalista.

Organização do manual: os manuais aqui analisados podem ser utilizados por jovens e adultos iniciantes ou não em FLE, e são acompanhados de guia pedagógico, livro do aluno, caderno de exercícios, CD-ROM, contendo de oito a doze unidades, cada unidade contempla as quatro competências de comunicação, sendo que Tempo 1 prioriza mais as atividades voltadas para a escrita e estudo da parte gramatical da língua francesa. Outro item a ser observado é que no manual Adosphère 1 o design gráfico das imagens e de algumas atividades apresen- 
tam-se um pouco desorganizado, comparativamente aos outros métodos analisados.

\subsection{Os manuais selecionados}

A partir dos resultados, dois apresentaram melhor perfil didático conforme a grade de análise de manuais de Silva (2014): Le Kiosque 1 (GALLON et al, 2007) e Taxi 1 (TA$\mathrm{XI}, 2005)$. Desta forma, estes dois métodos de ensino de FLE são os indicados para serem adotados, sendo o primeiro para o ensino fundamental e o segundo para o ensino médio, pelo fato dos mesmos atenderem aos requisitos de um bom manual para as práticas do ensino/aprendizagem em FLE e que estão mais próximos da metodologia de ensino, conteúdo, atividades dos professores das escolas públicas participantes desta pesquisa. Estes referidos manuais desenvolvem bem as quatro competências de comunicação, sem priorizar excessivamente a gramática, não tem excesso de imagens e apresentam adequada progressão de conteúdo.

\subsection{Le Kiosque 1 Méthode de Français}

Após análise do manual Le Kiosque (GALLON et al, 2007), por meio da grade de avaliação de manuais de Silva (2014), observou-se que o mesmo atende às necessidades dos professores e às dos alunos do nível de ensino fundamental. O primeiro ponto abordado na referida grade é o publico alvo: iniciantes em FLE e jovens. Em seguida, analisou-se a estrutura interna do manual. Le Kiosque (GALLON et al, 2007) apresenta sequência de conteúdo, de avaliação e de atividades para serem realizadas em classe e extraclasse, além de recapitulação de assuntos.
Figura 1 - Capa do livro Le Kioske 1 Méthode de Français Figure 1 - Book cover Le Kioske 1 Méthode de Français

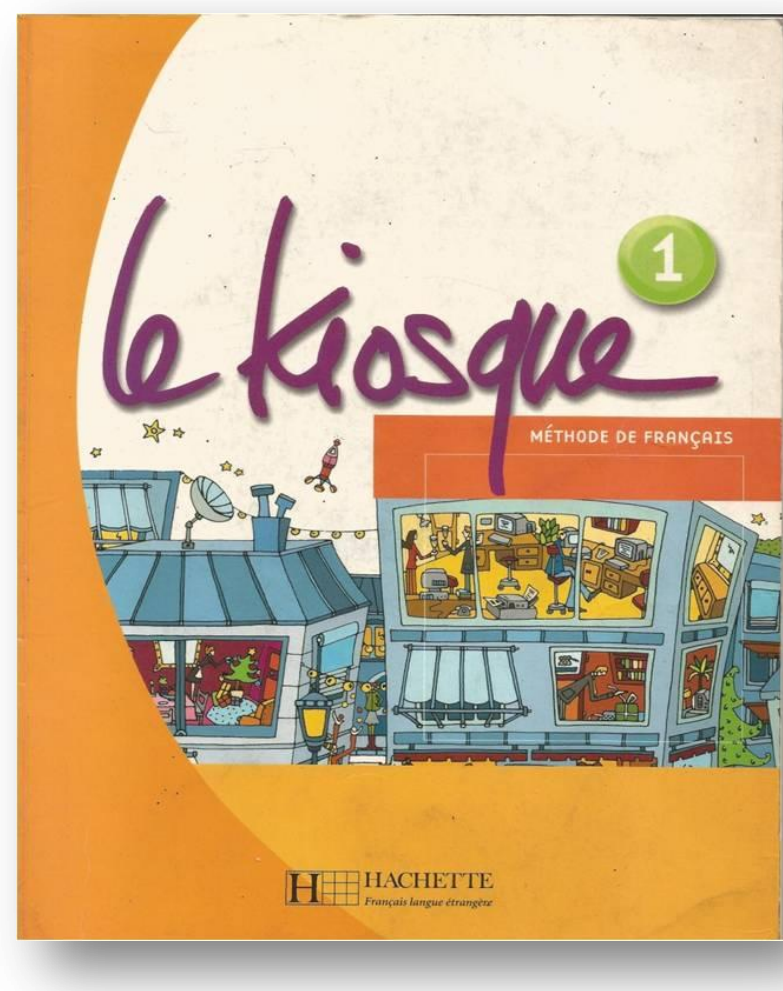

Os objetivos comunicativos do Le Kiosque 1 foram verificados ao longo das unidades, e são tarefas com o intuito de desenvolver no aluno as competências de comunicação, propiciando assim a autonomia do educando.

Com relação aos conteúdos, observou-se que são de fácil compreensão. As atividades são diversificadas, como por exemplo: de completar, de responder, de associar, de pronúncia e de compreensão oral. Tais atividades apresentam textos (histórias em quadrinhos, diálogos, letras de músicas, emails etc.) e imagens (pontos turísticos da França, fotos de pessoas famosas e que fizeram parte da história da França) com informações dos países que falam francês, da cultura da França e do cotidiano dos franceses.

Todos os diálogos presentes no manual possuem áudio de qualidade. As situações 
presentes nesses diálogos também estão de acordo com o público alvo: jovens estudantes, que possuem sonhos, atentos às tecnologias. No final de cada unidade há um teste que verifica se o aluno conseguiu assimilar o conteúdo e se consegue utilizar as quatro competências de comunicação.

\subsection{Taxi 1 Méthode de Français}

Por meio da grade de análise de manuais de Silva (2014), pode-se perceber que Taxi 1 (TAXI, 2005) é indicado para adolescentes e adultos, e não há a necessidade de o estudante ter prévio conhecimento na língua francesa. A duração do curso varia de 120 a 160 horas e tem como objetivo principal desenvolver o saber-fazer e o saber-ser dos alunos.

Figura 02 - Capa do livro Tempo 1 Méthode de Français Figure 02 - Book cover Tempo 1 Méthode de Français

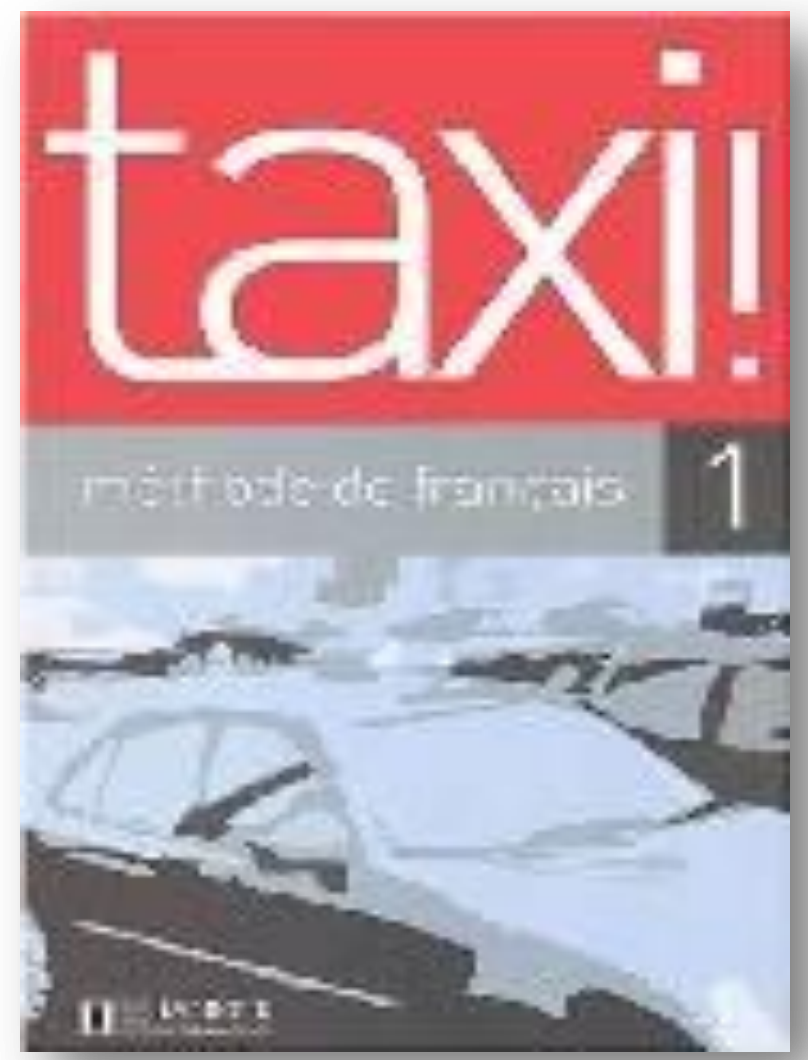

Taxi 1 (TAXI, 2005) apresenta-se com nove unidades, sendo que cada unidade possui quatro lições com páginas duplas. Cada unidade tem um objetivo específico. $\mathrm{Na}$ primeira unidade o aluno deverá saber apresentar a si e uma pessoa, oralmente e por escrito. Na segunda, escreverá um poema, uma carta postal. Na terceira, perguntará e indicará um caminho. Na quarta, deverá compreender o horário de um trem, falará sobre suas atividades nas mais diversas situações. Na quinta, descreverá os hábitos alimentares de seu país, contará a lembrança de uma festa. Na sexta, aceitará e recusará uma proposição. Na sétima, saberá falar de suas distrações, de sua opinião, de suas férias. Na oitava, falará de lembranças de infância, contará uma primeira experiência. Na nona, terá o domínio de alguns vocabulários relacionados ao tempo, fenômenos da natureza.

O manual Taxi 1 (TAXI, 2005) contempla uma variedade de gêneros textuais como: cartas, desenhos coloridos, mensagens de e-mails, canções, artigos de imprensa, mensagens publicitárias com os mais variados assuntos (moda, lugares, artistas etc.).

Os exercícios propostos são para serem feitos individualmente, em dupla ou em grupo. Há vários exercícios de escuta, de produção escrita e livre, além de exercícios para melhorar a pronúncia. No final de cada unidade há sempre uma avaliação do conteúdo denominada Bilan. Tal avaliação permite a revisão do assunto dado anteriormente e sempre no final de três unidades há uma avaliação denominada Préparation au DELF, para avaliar as quatro competências do aluno (expressão oral e escrita, compreensão oral e escrita).

Com relação ao léxico, conforme explicitado no prefácio do referido manual, é bas- 
tante rico, contando com mais de 800 palavras que vão se renovando a cada lição. Em relação à transcrição fonética, esta se restringe a atividade Prononcez, que tem como objetivo trabalhar a pronúncia.

A gramática é vista no início de cada lição e reforçada nas cinco páginas finais do manual e é apresentada explicitamente, pois aparece em todas as lições, e é dedutiva devida à forma como são apresentadas e cobradas nas atividades. Em relação aos conteúdos socioculturais temos a presença de imagens, que nos remetem aos principais pontos turísticos da França, seus hábitos diários, seus gostos alimentares, os seus anseios.

\section{CONSIDERAÇÕES FINAIS}

Pode-se perceber que a utilização do manual de FLE é uma forma prática e organizada do conteúdo a ser ministrado em sala de aula e também um instrumento pedagógico bastante eficaz na aprendizagem do idioma francês, pois com esta ferramenta disponível o próprio aluno terá como se autoavaliar e progredir em seu aprendizado, deixando-o mais seguro em seu processo de aprendizado, visto que em situações extraclasse ele poderá utilizar o suporte didático contido em um manual, tais como: vocabulário, exercícios, diálogos escritos e orais.

Diante do que foi explicitado, enfatizamos a importância de um método de FLE, visando sensibilizar não somente educadores como também todos os envolvidos no processo da educação básica, particularmente no município de Macapá-AP. Dadas todas as vantagens que um método de ensino apresenta, fica claro que o mesmo deve ser utilizado. Em razão da ausência institucionalizada de manuais de idiomas e a indefinição de um método único a ser trabalhado nas escolas, o aprendizado de FLE continua sem bases didático-metodológicas claramente definidas, e que em função disso o processo de ensino-aprendizagem fica sem uma progressão linear.

Como se vê, a argumentação acima exposta demonstra que diante da ausência de um método de FLE, os professores se veem tendo que desenvolver um trabalho isolado e sem um suporte que poderia estar orientando adequadamente os alunos nos trabaIhos escolares e nas práticas sociais extraclasses.

Por fim, este trabalho apresenta sua contribuição sobre a importância na seleção e uso de manuais de FLE no processo de ensino-aprendizagem em escolas públicas estaduais no Estado do Amapá, e que isto venha a ser discutido e viabilizado pela Secretaria de Educação, dentro da política do livro didático como elemento auxiliador de ensino.

\section{REFERÊNCIAS}

BESSE, H. Méthodes et pratiques des manuels de langue. Paris: Didier-Crédif, 1985. BRASIL. Parâmetros curriculares nacionais: terceiro e quarto ciclos do ensino fundamental - língua estrangeira. Brasília: MEC/SEF, 1998.

GALLON, F. et al. Le Kiosque Méthode de Français. Paris: Hachette, 2007.

HIMBER, C.; POLETTI M.-L. Adosphère 1 Méthode de Français. Paris: Hachette, 2011.

LAVENNE, C.; BÉRARD, É.; CANIER, Y. Tempo 1 Méthode de Français. Paris: Didier/Hatier, 1996.

PRÁCE, B. Analyse didactique d'un manuel du FLE et ses compléments possibles sur internet. 2011. 82 p. Dissertação - Pedago- 
gická Fakulta, Masarykova Univerzita, Brno, 2011.

PRODANOV, C. C.; FREITAS, E. C. de. Metodologia do trabalho científico: métodos e técnicas da pesquisa e do trabalho acadêmico. 2. ed. Novo Hamburgo: Feevale, 2013. SAVLI, F. Analyse des méthodes de FLE: techniques et pratiques. S.I., 2011.

SILVA, B. T. F. da. Fiche d'évaluation. Macapá, 2014.

TAXI Méthode de Français. Paris: Hachette, 2005.

TILIO, R. O papel do livro didático no ensino de língua estrangeira. Revista Eletrônica do Instituto de Humanidades, v. 7, n. 26, jul./set. 2008.

VILAÇA, M. L. C. Materiais didáticos no ensino de língua estrangeira: aspecto de análise, avaliação e adaptação. Revista Eletrônica do Instituto de Humanidades, Rio de Janeiro, v. 8, n. 32, jul./set., 2010.

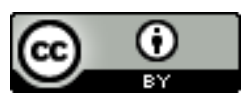

License information: This is an openaccess article distributed under the terms of the Creative Commons Attribution License, which permits unrestricted use, distribution, and reproduction in any medium, provided the original work is properly cited.

Artigo recebido em 11 de julho de 2017.

Avaliado em 29 de agosto de 2017.

Aceito em 20 de setembro de 2017.

Publicado em 22 de setembro de 2017.

\section{Como citar este artigo (ABNT):}

AMORAS, Aluana Vilhena; ARAÚJO, Mônica

Miranda Oliveira de; ALVES, Valmira dos Santos Cordeiro. A importância do manual de FLE em escolas públicas estaduais no município de Macapá-AP. Estação Científica (UNIFAP), Macapá, v. 7, n. 2, p. 77-86, maio/ago. 2017. 